\title{
Piracy, indirect « Sampling » and sequential adoption of TV series with multiple episodes
}

Maher Gordah, Thomas Le Texier and Moustapha Niang

\section{(2) OpenEdition \\ Journals}

Electronic version

URL: https://journals.openedition.org/rei/5423

DOI: $10.4000 /$ rei.5423

ISSN: $1773-0198$

Publisher

De Boeck Supérieur

\section{Printed version}

Date of publication: 15 September 2012

Number of pages: 9-25

ISSN: 0154-3229

\section{Electronic reference}

Maher Gordah, Thomas Le Texier and Moustapha Niang, "Piracy, indirect « Sampling » and sequentia adoption of TV series with multiple episodes", Revue d'économie industrielle [Online], 139 | 3ème trimestre 2012, Online since 15 September 2014, connection on 02 June 2022. URL: http:// journals.openedition.org/rei/5423 ; DOl: https://doi.org/10.4000/rei.5423 


\section{PIRACY, INDIRECT «SAMPLING » AND SEQUENTIAL ADOPTION OF TV SERIES WITH MULTIPLE EPISODES}

Mots-clés : Piratage, échantillonnage indirect, VoD, séries télévisées à épisodes multiples, adoption séquentielle.

Key words : Piracy, Indirect Sampling, VoD, TV Series With Multiple Episodes, Sequential Adoption.

\section{I. - INTRODUCTION}

The development of compression standards has led to the « dematerialization era » and to the widespreading of digital files online (Shapiro and Varian, 1998; Varian, 2000; Hui and Png, 2003; Chellappa and Shivendu, 2005; Peitz and Waelbroeck, 2006a; Belleflamme and Peitz, 2010). As such digital goods used to be illegally distributed via dedicated parallel networks (e.g., peer-topeer networks), many commercial players have perceived their popularity as a direct threat for their own activities, resulting from the increasing abilities of users to participate in productive activities (Toffler, 1980; von Hippel, 1988; von Hippel, 2005; Flowers, 2008). Although many see in the developing of « outlaw » activities the main reason for the empirically observed recent losses in the sales of cultural goods (Liebowitz, 2006; Zentner, 2006), legal tools have been found to be somewhat inefficient when facing the technical features of illegal distribution architectures (Park and Scotchmer, 2005; Banerjee et $a l ., 2008)$. Following the appearance of online streaming services which have

(*) The authors are very grateful to two anonymous referees for their helpful comments on a previous version of this paper. 
massively led to the developing of illegal networks, some players (e.g., MGM in the U.S. and Orange or TF1 in France) have developed new services by providing access to digital goods according to a commercial scheme. Such a situation reflects that a growing number of commercial entities have left their traditional - legal - way of fighting against the providers of illegal digital goods and have adapted by developing new business opportunities. The VoD Video on Demand - commercial activity represents one of the most popular models according to which commercial players attempt to react to the socalled « pirate » threat. This switch may be perceived as an attempt by commercial players to turn to a one-to-one competition while using their opponents' technology and not strictly focusing on the illegal nature of their activity.

One key research question is to identify the reasons why commercial players have developed such a competition behavior towards the players they previously used to sue. One may notably wonder why commercial players are currently willing to act by setting up a $\mathrm{VoD}$ commercial activity and how they are nowadays likely to apprehend piracy. Although such a switch may at first sight seem surprising, an increasing body of literature has stressed that piracy could be paradoxically beneficial to commercial activities. Several major contributions have highlighted the importance of network effects in the valuation of commercial profit and therefore the positive effect of piracy when network effects are likely to be high-leveled (Liebowitz, 1985; Besen and Kirby, 1989; Conner and Rumelt, 1991; Takeyama, 1994; Shy and Thisse, 1999).

Dealing with digital goods, « sampling » has been shown to have a significant positive impact on the enhancement of the sales of commercial digital goods (Bounie et al., 2005; Bounie et al., 2006, Peitz and Waelbroeck, 2006b ; Danaher et al., 2010; Smith and Telang, 2010) as well the increase of the popularity of the artists concerned (Gayer and Shy, 2006; Gopal et al., 2006; Alcalá and González-Maestre, 2010). « Sampling » in technological adoption patterns is likely to apply in the case of digital goods inasmuch as these can be seen as experience goods. Here, the "sampling » effect enables adopters to develop learning capabilities and to use them when adopting other goods. «Sampling » can thus be seen as a means for agents to select the products that better meet their expectations according to a somewhat « learning-by-using » scheme. Considering « sampling » in the shaping of adoption trajectories, one may easily think that commercial players might benefit from illegal diffusion sources (e.g., illegal file-sharing and illegal streaming). Indeed, previous illegal adoption might allow commercial players to enhance their sales because adopters are more likely to improve the match between their tastes and the characteristics of the commercial products.

Focusing on the case of music, Peitz and Waelbroeck (2006b) develop a theoretical model to analyze the impact of the "sampling » effect on sales when piracy applies. Their main result is that illegal activities enable commercial players to reach out higher profits thanks to the «sampling » effect 
when tastes are sufficiently heterogeneous and products are differentiated enough. The empirical study of Bounie et al. (2006) estimates the impact of piracy of the commercial demand for movies. The authors show that a significant share of pirates eventually increases their demand for commercial goods.

As a matter of fact, the importance of the «sampling » effect is not the same according to the nature of the digital goods which are analyzed. As already stressed by Bounie et al. (2006), adopters are likely to listen to the same song several times whereas they are less likely to watch the same movie as often. We therefore suggest that the role of « sampling » on commercial adoption is highly related to the way digital goods are set to be consumed. Another case of digital goods is that of TV series with multiple episodes. In this specific case, digital goods are complementary goods which are initially released to be adopted in a sequential way and the goal of the commercial provider is to create a lock-in so as to lead adopters to purchase. Consequently, the «sampling » effect should be here seen as an effect according to which the - previous adoption of goods is likely to influence that of - following - others. We thus introduce a definition of - indirect - « sampling » which differs from that of Peitz and Waelbroeck (2006b). As such, it also appears appropriate to consider a framework in which an agent who previously adopted a digital good from an illegal platform does not intend to later purchase the same digital good from a commercial provider.

Introducing the indirect « sampling » effect in the analysis of commercial adoption patterns is also relevant to identify to what extent illegal activities have a detrimental impact on social welfare outcomes. This research question remains of major interest, as efforts against such activities (e.g., file-sharing, streaming) are still intensively carried out by both private groups (e.g., the RIAA and the MPAA, namely Recording Industry Association of America and Motion Picture Association of America in the U.S.) and public authorities (e.g., the French Government). Focusing on the French case, both DADVSI and HADOPI laws have revealed the willingness of French authorities to find ways to prevent users from adopting goods from «pirate » networks. However, the scope of such public policies has to be identified to see if regulation towards illegal activities delivers the best social outcomes.

We analyze the impact of the illegal - downloading/streaming - activity on the VoD commercial activity, as well as the role of indirect « sampling » in the designing of suitable pricing strategies. To do so, we here consider the case of TV series with multiple episodes which are expected to be adopted in a sequential way. Building on the theoretical framework developed by Peitz and Walbroeck (2006b), we notably present a model in which adopters may decide to adopt a digital file by purchasing it, adopt it by getting it from an illegal platform or not to adopt it. Here, « sampling » effects are likely to apply when a product is adopted from either commercial or illegal activities, but we suppose that adopters are able to correct a higher-leveled information bias when 
purchasing. We identify optimal pricing and related profits. Welfare outcomes are also dealt.

Our results reveal that the outcomes of the VoD commercial provider differ whether the illegal downloading/streaming activity applies or not and when « sampling » is considered in the designing of pricing strategies or not. We find that the $\mathrm{VoD}$ commercial provider always benefits from integrating indirect «sampling » in her pricing scheme. However, this strategy does not lead her to systematically benefit from illegal activities. Indeed, her commercial outcome directly depends on the combined effect of two opposite effects, namely « direct piracy » effect and « differential sampling » effect. From a regulatory point of view, we do not find any evidence of detrimental effects illegal activities have on welfare. Our results rather exhibit that suitable - here « sampling »- friendly - pricing strategies have to be developed to increase welfare levels.

The organization of the paper is as follows. We first present the settings of the model (II.). We secondly identify commercial and social welfare outcomes by considering four cases (i.e., no downloading/streaming - no " sampling », no downloading/streaming - « sampling », downloading/streaming - no « sampling » and downloading/streaming - « sampling ») and we hold a comparative analysis (III.). We thirdly conclude and provide directions for further research (IV.).

\section{II. - THE MODEL}

We present a market in which all the digital goods (i.e., TV series with multiple episodes) are available on both VoD commercial platforms and illegal platforms. However, we suggest that the contents which are available on each type of platforms may slightly differ. Indeed, illegal platforms are likely to provide episodes which are ripped from TV airings whereas VoD commercial platforms may offer original features or extended versions which have not been aired on TV. We thus call « product » the digital good which is available on the VoD commercial platform whereas we use the term « variant» to refer to its illegal version.

The VoD commercial provider acts as a monopolist and offers $N$ products ( $N$ $\geq 2$ ). As in Peitz and Waelbroeck (2006b), product differentiation is introduced by using the Salop circle of unit length on which products are equidistantly located. We define $l_{x}$ as the location of each product on the circle $(x \in[1 ; N])$. The VoD commercial provider sets her profit-maximizing strategy by defining optimal prices for the products she provides in her catalog. As generally assumed, and due to the informational nature of digital goods and their reproduction facilities, the marginal costs of production are set to zero. Fixed costs $(K)$ here apply and represent the costs the $\mathrm{VoD}$ commercial provider has to face when acquiring the rights to distribute all the products available in her catalog. 
On the demand side, we consider technological adopters who are uniformly distributed on the circle and whose total mass is equal to 1. Adopters exhibit an ideal intrinsic preference when adopting a digital good that perfectly meets their needs. Such a good is characterized by its location $\bar{l}$. Supposing that a consumer adopts a digital good whose location is $l_{x}$, she gets a gross surplus equal to $r-t\left|l-l_{x}\right| . r$ represents the surplus adopters benefit from adopting at $l$ and $t$ is the traditional transportation cost parameter used when formalizing product differentiation. In addition, we consider that adopters derive an additional benefit $\alpha / 2$ from purchasing. $\alpha$ represents the quality of the service that is provided by the commercial player (e.g., legal streaming or downloading, HD or SD quality of the file available).

We focus on the case of sequential adoption of two digital goods. Hence, we here attempt to identify to what extent illegal activities lead the VoD commercial provider to revise her pricing strategy to reach out optimal outcomes. We thus define the adoption decision process as a three-step game :

- at step 0 , the VoD commercial provider releases $N$ products and defines her pricing strategy $\left(p_{1} ; p_{2}\right)$ for two products which are provided to be sequentially adopted, namely products 1 and 2 . At the same time, the illegal platform provides $N$ variants;

- at step 1, adopters decide to adopt product 1, to adopt the variant of product 1 (i.e., variant 1 ), or not to adopt among the previously released $N$ products/variants ;

- at step 2, adopters decide to adopt product 2, to adopt the variant of product 2 (i.e., variant 2), or not to adopt among the remaining $N-1$ products/variants.

The adopters have full and common knowledge of the pricing strategy of the VoD commercial provider. She clearly reveals her pricing rule at step 0 , thus using a linear pricing scheme $\left(p_{1}=p_{2}\right)$, a decreasing pricing scheme $\left(p_{1}>p_{2}\right)$ or an increasing pricing scheme $\left(p_{1}<p_{2}\right)$. A decreasing pricing scheme can be seen as a strategy which aims at keeping customers loyal by offering them lower prices over time. In contrast, an increasing pricing scheme should be interpreted as a commercial attempt to attract new customers by offering them low prices before charging them higher prices for further purchases.

The adoption patterns of product/variant 2 may somewhat depend on that of product/variant 1 . Product/variant 1 and product/variant 2 are likely to deliver the same level of ideal preference to their adopters (i.e., $r$ ). The pricing strategy of the firm consequently depends on related adoption issues. We denote the adoption strategies as $\left(a_{1} ; a_{2}\right)$, where $a_{1}=\left\{b_{1} ; d_{1} ; \varnothing_{1}\right\}$ and $a_{2}=\left\{b_{2} ; d_{2}\right.$; $\left.\varnothing_{2}\right\} . b_{1}$ (resp. $b_{2}$ ) represents a product 1 (resp. product 2) purchase strategy, whereas $d_{1}$ (resp. $d_{2}$ ) represents a variant 1 (resp. variant 2) illegal down- 
load/streaming strategy and $\varnothing_{1}\left(\right.$ resp. $\varnothing_{2}$ ) represents a product/variant 1 (resp. product/variant 2) non-adoption strategy.

\section{III. - OPTIMAL PRICING STRATEGIES, PROFITS AND WELFARE}

We analyze the optimal pricing rules that the $\mathrm{VoD}$ commercial provider has to design for her activity to be sustainable (i.e., for product 2 to be sold). Thus, her pricing decision-making is based on a backward scheme, inasmuch as she sets a price for product 2 so that it enables her to fully extract the surplus of the adopters at step 2. She then sets the highest level of price for product 1 so that all the adopters are encouraged to adopt product 1. Adoption strategies provide utilities whose levels are defined by the following utility functions :

$$
v\left(a_{1} ; a_{2}\right)=\left\{\begin{array}{l}
v\left(b_{1} ; b_{2}\right)=2 r+\alpha-t\left|\bar{l}-l_{i}\right|-t\left|\bar{l}-l_{j}\right|-p_{1}-p_{2} \\
v\left(b_{1} ; \varnothing_{2}\right)=r+\alpha / 2-t\left|\bar{l}-l_{i}\right|-p_{1} \\
v\left(\varnothing_{1} ; b_{2}\right)=r+\alpha / 2-t\left|\bar{l}-l_{j}\right|-p_{1} \\
v\left(\varnothing_{1} ; \varnothing_{2}\right)=0 \\
v\left(d_{1} ; d_{2}\right)=2 r-t\left|\bar{l}-l_{i}\right|-t\left|\bar{l}-l_{j}\right|-2 s \\
v\left(d_{1} ; b_{2}\right)=2 r+\alpha / 2-t\left|\bar{l}-l_{i}\right|-t\left|\bar{l}-l_{j}\right|-p_{2}-s \\
v\left(d_{1} ; \varnothing_{2}\right)=r-t\left|\bar{l}-l_{i}\right|-s \\
v\left(b_{1} ; d_{2}\right)=2 r+\alpha / 2-t\left|\bar{l}-l_{i}\right|-t\left|\bar{l}-l_{j}\right|-p_{1}-s \\
v\left(\varnothing_{1} ; d_{2}\right)=r-t\left|\bar{l}-l_{j}\right|-s
\end{array}\right.
$$

When adopters select variant 1 and/or variant 2 , we suggest that they face a cost which represents the disutility they may get from it (e.g., length of search processes, threats of legal lawsuits, technical constraints, etc.). $l_{i}$ (resp. $l_{j}$ ) represents the location of the product that technological adopters select at step 1 (resp. 2). We set to zero the level of utility of an agent who neither adopts product/variant 1 nor product/variant 2 (i.e., $v\left(\varnothing_{1} ; \varnothing_{2}\right)=0$ ). The value of $\left|\bar{l}-l_{j}\right|$ depends on the learning capabilities potential adopters are likely to develop when previously adopting related goods. The values of $\left|\bar{l}-l_{x}\right|(x=\{i$, $j\}$ ) are estimated by calculating their expected values. Such values are likely to differ, depending on the cases we next study.

\subsection{Optimal pricing strategy when illegal downloading/streaming is not possible}

When illegal download/streaming is not possible, four adoption strategies are possible:

$$
\left(a_{1} ; a_{2}\right)=\left\{\left(b_{1} ; b_{2}\right),\left(b_{1} ; \varnothing_{2}\right),\left(\varnothing_{1} ; b_{2}\right),\left(\varnothing_{1} ; \varnothing_{2}\right)\right\}
$$


As adopters have to define their adoption strategies in an imperfect informational framework, pricing strategies also depend on the abilities that the firm has to take « sampling » into account.

\subsubsection{No « sampling » effect}

When « sampling » effects are not taken into account in this framework, the product that best meets the expectations of an adopter is located at $l_{x}=\bar{l}$, whereas the product that is the most inappropriate to her is located at $l_{x}$ so that $\left|\bar{l}-l_{x}\right|=1 / 2$. The expected utility functions of the users are expressed as follows :

$$
u\left(a_{1} ; a_{2}\right)=\left\{\begin{array}{l}
u\left(b_{1} ; b_{2}\right)=2 r+\alpha-t / 2-p_{1}-p_{2} \\
u\left(b_{1} ; \varnothing_{2}\right)=r+\alpha / 2-t / 4-p_{1} \\
u\left(\varnothing 1 ; b_{2}\right)=r+\alpha / 2-t / 4-p_{2} \\
u\left(\varnothing_{1} ; \varnothing_{2}\right)=0
\end{array}\right.
$$

Lemma 1. When illegal downloading/streaming is not possible and " sampling " effects are not considered, the VoD commercial provider sets out linear pricing rule $\left(p_{1}^{*} ; p_{2}^{*}\right)=(r+\alpha / 2-t / 4 ; r+\alpha / 2-t / 4)$ and makes profit $\pi^{*}=2 r+\alpha-t / 2-K$. See Appendix 1 .

Assumption 1. When illegal dowloading is impossible, the VoD commercial provider can generate profits from her activity, i.e., $2 r+\alpha-t / 2-K \geq 0$.

Assumption 1 stresses that transportation costs and production costs are likely to be overcome by the benefits the adopters get from the purchase of both product 1 and product 2 .

\subsection{2. « Sampling » effect}

When « sampling » effects are taken into account, adopters can develop learning capabilities about the location of the product that best meets their needs. Indeed, they get additional information from previous consumption (i.e., consumption of product 1) and uncertainty is likely to be weakened. Here, following the purchase of product 1 , the next product (i.e., product 2 ) that best meets the expectations of an adopter is located at $l_{x}=\bar{l}$, whereas the product that is the most inappropriate to her is located at $l_{x}$ so that $\left|\bar{l}-l_{x}\right|=1 / 2 N$. The expected utility functions of the adopters are thus expressed as follows:

$$
u\left(a_{1} ; a_{2}\right)=\left\{\begin{array}{l}
u\left(b_{1} ; b_{2}\right)=2 r+\alpha-t / 4-t / 4 N-p_{1}-p_{2} \\
u\left(b_{1} ; \varnothing_{2}\right)=r+\alpha / 2-t / 4-p_{1} \\
u\left(\varnothing 1 ; b_{2}\right)=r+\alpha / 2-t / 4-p_{2} \\
u\left(\varnothing_{1} ; \varnothing_{2}\right)=0
\end{array}\right.
$$

Lemma 2. When illegal downloading/streaming is not possible and "sampling » effects are considered, the VoD commercial provider sets out increa- 
sing pricing rule $\left(p_{1}^{*} ; p_{2}^{*}\right)=(r+\alpha / 2-t / 4 ; r+\alpha / 2-t / 4 N)$ and makes profit $\pi^{*}=2 r+\alpha-t / 4-t / 4 N-K$. See Appendix 2 .

From Assumption 1, one can easily find that $\pi^{*}=2 r+\alpha-t / 4-t / 4 N-K>0$.

\subsection{Optimal pricing rule when illegal downloading/streaming is introduced}

When illegal downloading/streaming is introduced, nine adoption strategies are possible: $\left(a_{1} ; a_{2}\right)=\left\{\left(b_{1} ; b_{2}\right),\left(b_{1} ; \varnothing_{2}\right),\left(\varnothing_{1} ; b_{2}\right),\left(\varnothing_{1} ; \varnothing_{2}\right),\left(d_{1} ; d_{2}\right),\left(d_{1}\right.\right.$; $\left.\left.b_{2}\right),\left(d_{1} ; \varnothing_{2}\right),\left(b_{1} ; d_{2}\right),\left(\varnothing_{1} ; d_{2}\right)\right\}$

\subsubsection{No « sampling » effect}

When « sampling » effects are not taken into account, the digital good that best meets the expectations of an adopter is located at $l_{x}=\bar{l}$, whereas the digital good that is the most inappropriate to her is located at $l_{x}$ so that $\left|\bar{l}-l_{x}\right|=$ $1 / 2$. The expected utility functions of the users are expressed as follows:

$$
u\left(a_{1} ; a_{2}\right)=\left\{\begin{array}{l}
u\left(b_{1} ; b_{2}\right)=2 r+\alpha-t / 2-p_{1}-p_{2} \\
u\left(b_{1} ; \varnothing_{2}\right)=r+\alpha / 2-t / 4-p_{1} \\
u\left(\varnothing_{1} ; b_{2}\right)=r+\alpha / 2-t / 4-p_{2} \\
u\left(\varnothing_{1} ; \varnothing_{2}\right)=0 \\
u\left(d_{1} ; d_{2}\right)=2 r-t / 2-2 s \\
u\left(d_{1} ; b_{2}\right)=2 r+\alpha / 2-t / 2-p_{2}-s \\
u\left(d_{1} ; \varnothing_{2}\right)=r-t / 4-s \\
u\left(b_{1} ; d_{2}\right)=2 r+\alpha / 2-t / 2-p_{1}-s \\
u\left(\varnothing_{1} ; d_{2}\right)=r-t / 4-s
\end{array}\right.
$$

Assumption 2. Differentiation parameter $t$ is defined so that $4(r-s) \geq t>0$.

We assume that commercial players are not likely to incite adopters not to download pirate digital goods when defining their offer strategy.

Lemma 3. When illegal downloading/streaming is possible and "sampling » effects are not considered, the VoD commercial provider sets out linear pricing rule $\left(p_{1}^{*} ; p_{2}^{*}\right)=(\alpha / 2+s ; \alpha / 2+s)$ and makes profit $\pi^{*}=\alpha+2 s-K$ if $K \leq \alpha+2$ s. If $K>\alpha+2 s$, she does not provide digital goods and $\pi^{*}=0$. See Appendix 3.

As found in 3.1.1., the VoD commercial provider is likely to apply a linear pricing strategy to maximize her profit when illegal downloading/streaming is introduced. 


\subsection{2. « Sampling » effect}

When « sampling » is introduced into the pricing decision of the VoD commercial provider, she considers that adopters get additional information from previous consumption (i.e., consumption of product/variant 1). We nevertheless suggest that modes of consumption (i.e., purchase and illegal downloading/streaming) are likely to deliver different learning outcomes. Moreover, we state that adopters better correct informational uncertainty when purchasing than when adopting from an illegal platform. Our view is that learning disturbances are likely to apply following the adoption of variant 1 . Our first motive is that variants may slightly differ from products. Adopting variants thus provide lesser abilities to generate a high level of correction when informing the adopters about the product which best meets their needs. Our second motive is that other detrimental effects may also apply in the case of illegal adoption. For instance, illegal platforms generally offer communication features (e.g., message boards, chatrooms) which may eventually lead to the provision of spoilers if they are not correctly managed. Such spoilers are harmful for adopters since these are likely to inform them about critical events in the storyline of TV series. In some cases, spoilers give them a wrong view about the value they may derive from the TV series if seen in a proper (i.e., sequential) way, as explicitly designed by the official provider.

On the one hand, following the purchase of product 1, the next product (i.e., product 2) that best meets the expectations of an adopter is located at $l_{x}=\vec{l}$, whereas the product that is the most inappropriate to her is located at $l_{x}$ so that $\left|\bar{l}-l_{x}\right|=1 / 2 N$. On the other hand, following the adoption of variant 1 , product 2 that best meets the expectations of adopter is located at $l_{x}=\bar{l}$, whereas the product that is the most inappropriate to her is located at $l_{x}$ so that $\left|\bar{l}-l_{x}\right|=1 / 4$. The expected utility functions of the users are expressed as follows:

$$
u\left(a_{1} ; a_{2}\right)=\left\{\begin{array}{l}
u\left(b_{1} ; b_{2}\right)=2 r+\alpha-t / 4-t / 4 N-p_{1}-p_{2} \\
u\left(b_{1} ; \varnothing_{2}\right)=r+\alpha / 2-t / 4-p_{1} \\
u\left(\varnothing_{1} ; b_{2}\right)=r+\alpha / 2-t / 4-p_{2} \\
u\left(\varnothing_{1} ; \varnothing_{2}\right)=0 \\
u\left(d_{1} ; d_{2}\right)=2 r-3 t / 8-2 s \\
u\left(d_{1} ; b_{2}\right)=2 r+\alpha / 2-3 t / 8-p_{2}-s \\
u\left(d_{1} ; \varnothing_{2}\right)=r-t / 4-s \\
u\left(b_{1} ; d_{2}\right)=2 r+\alpha / 2-t / 4-t / 4 N-p_{1}-s \\
u\left(\varnothing_{1} ; d_{2}\right)=r-t / 4-s
\end{array}\right.
$$

Lemma 4. When illegal downloading/streaming is possible and "sampling » effects are not considered, the VoD commercial provider sets out decreasing pricing rule $\left(p_{1}^{*} ; p_{2}^{*}\right)=(\alpha / 2+s+t / 8-t / 4 N ; \alpha / 2+s)$ and makes profit $\pi^{*}=$ $\alpha+2 s+t / 8-t / 4 N-K$ if $K \leq \alpha+2 s+t / 8-t / 4 N$. If $K>\alpha+2 s+t / 8-t / 4 N$, she does not provide digital goods and $\pi^{*}=0$. See Appendix 4 . 
In a framework in which illegal platforms are introduced, the VoD commercial provider sets out an optimal linear pricing rule when she does not take learning effects into account, whereas she sets an optimal decreasing one when she considers « sampling ».

\subsection{Analyzing the impact of illegal downloading/streaming on profit and welfare}

\subsubsection{Profits}

We first hold a comparative analysis to investigate to what extent profits evolve when illegal downloading/streaming is introduced and/or "sampling » is taken into account by the VoD commercial provider when designing her price strategy.

Proposition 1. The level of profit the VoD commercial provider obtains when "sampling » is introduced is higher than that reached out when "sampling » is not considered, all other things being equal.

Proof of Proposition 1. As $t / 4>t / 4 N, t / 2>t / 4+t / 4 N$. As a consequence, $2 r$ $+\alpha-t / 4-t / 4 N-K>2 r+\alpha-t / 2-K$. Besides, let us suppose that $K \leq \alpha+$ $2 s$. As $N \geq 2, t / 8 \geq t / 4 N$. Therefore, $\alpha+2 s+t / 8-t / 4 N-K \geq \alpha+2 s-K$.

The VoD commercial provider's account for sampling effects in her pricing decision-making is likely to increase her profit, all other things being equal. Such a concern leads her to develop non-linear (i.e., increasing or decreasing) pricing rules to extract a higher surplus than when learning effects are not taken into account. One can easily observe that the highest level of profit the VoD commercial provider can reach out is obtained when she takes «sampling » into account in framework in which the illegal downloading/streaming activity does not apply. In a similar fashion, the lowest level of profit the commercial VoD provider can reach out is obtained when she does not take « sampling » into account in a framework in which the illegal downloading/streaming activity applies. Alternative commercial outcomes are nevertheless somehow more involved to compare. Indeed, we find that the profit which is reached out when «sampling » is taken into account and the illegal downloading/streaming activity applies is higher-leveled than that which is reached out when "sampling » is not taken into account in a context in which the illegal downloading/streaming activity does not apply when the following inequality holds :

$2(r-s) \leq(t / 8-t / 4 N)-(-t / 2)$.

(1) Let us note that $(r-s)>0$ from assumption 2 . In addition, as $N \geq 2$, we find that $(t / 8-t / 4 N)-(-t / 2)>0$. 


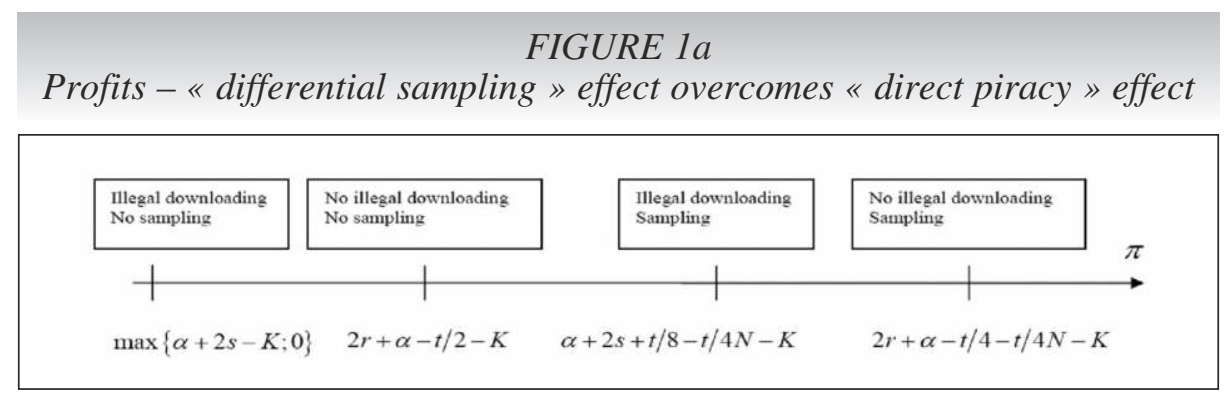

FIGURE $1 b$

Profits - « direct piracy » effect overcomes « differential sampling » effect

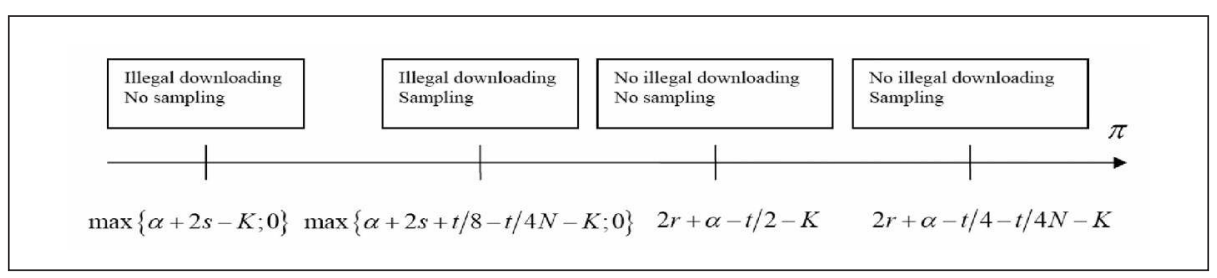

The interpretation of this condition can be explained in terms of two opposite effects, namely « direct piracy » effect and « differential sampling » effect. On the one hand, the «direct piracy effect » is related to the incentives of the adopters to get digital files from illegal platforms, which is here captured by $s$. Such an effect is obviously found to be harmful to the VoD commercial provider. On the other hand, the «differential sampling effect» results from the additional learning the adopters generate from acquiring digital files from illegal platforms rather than the $\mathrm{VoD}$ commercial provider. As the VoD commercial provider can partially extract a larger part of the surplus of her customers when the illegal downloading/streaming activity is introduced, we find that the « differential sampling effect » positively impacts on her profit. This effect is here captured by $(t / 8-t / 4 N)-(-t / 2)$. As such, the combined effect of both « direct piracy » effect and « differential sampling » effect is shown to be profitable for the VoD commercial provider when the "differential sampling » effect is greater than the « direct piracy » effect (figure 1a). When the " direct piracy » effect overcomes the « differential sampling » effect, the introduction of the illegal downloading/streaming activity is always found to lead to lower-leveled profits (figure 1b).

From both figure 1a and figure 1b, we see that the illegal downloading/streaming activity is detrimental to the $\mathrm{VoD}$ commercial activity, whether « sampling » is considered or not. Indeed, when only considering the « direct piracy » effect, we do not evidence any potential profit-enhancing effect from outlaw activities. 


\subsubsection{Welfare}

We analyze the impact of both " sampling » and outlaw activities on welfare so as to point out suitable public policies. At the optimal state, the pricing strategy of the VoD commercial provider is set out so that all the agents purchase the official digital goods available on the VoD commercial platform. Welfare is then defined as the sum of adopters' and VoD commercial provider's surplus, i.e.,

$$
W=C S_{V o D}+\pi^{*}=\int_{n=0}^{1} u^{*}\left(b_{1} ; b_{2}\right) \mathrm{d} n+\pi^{*}=u^{*}\left(b_{1} ; b_{2}\right)+\pi^{*} .
$$

Table 1 displays the levels of profit, adopters' surplus and ensuing welfare obtained at the optimal state, according to both the way the commercial VoD provider takes « sampling » into account in her pricing strategy and the likelihood of illegal activities to apply or not.

TABLE 1 - Profits, adopters' surplus and welfare

\begin{tabular}{|c|c|c|}
\hline $\begin{array}{c}\text { No illegal } \\
\text { downloading/ } \\
\text { streaming }\end{array}$ & $\left\{\begin{array}{l}C S_{V o D}=0 \\
\pi^{*}=2 r+\alpha-t / 2-K \\
W=2 r+\alpha-t / 2-K\end{array}\right.$ & $\left\{\begin{array}{l}C S_{V o D}=0 \\
\pi^{*}=2 r+\alpha-t / 4-t / 4 N-K \\
W=2 r+\alpha-t / 4-t / 4 N-K\end{array}\right.$ \\
\hline $\begin{array}{c}\text { Illegal } \\
\text { downloading/ } \\
\text { streaming }\end{array}$ & $\left\{\begin{array}{l}C S_{V o D}=2 r-2 s-t / 2 \\
\pi^{*}=\alpha+2 s-K \\
W=2 r+\alpha-t / 2-K\end{array}\right.$ & $\left\{\begin{array}{l}C S_{V o D}=2 r-2 s-3 t / 8 \\
\pi^{*}=\alpha+2 s+t / 8-t / 4 N-K \\
W=2 r+\alpha-t / 4-t / 4 N-K\end{array}\right.$ \\
\hline
\end{tabular}

From Table 1, we see that the illegal downloading/streaming activity does not have an impact on welfare levels. The interpretation of this result is that the « direct piracy » effect leads to a full transfer of utility from the VoD commercial provider to the adopters. However, the likelihood of the VoD commercial provider to take « sampling » into account in her pricing strategy positively impacts on welfare. One explanation is that only the « differential sampling » effect leads to a welfare increase because it enables the VoD commercial provider to - yet partially - extract a higher level of surplus from the adopters. Welfare levels only thus depend on the abilities of the VoD commercial provider to integrate « sampling » into her pricing scheme.

Such findings clearly exhibit a conflict of interest between adopters and the VoD commercial provider. Illegal activities have ceteris paribus been shown to be detrimental to commercial activities because they prevent the VoD commercial provider from fully extracting the adopters' surplus. However, we do not find any evidence of detrimental effects illegal activities may have on welfare. Our results rather exhibit that suitable - here « sampling » - friendlypricing strategies have to be developed to increase welfare levels. 


\section{IV. - DISCUSSION AND FURTHER RESEARCH}

In this article we have presented a model to analyze the impact of the illegal downloading/streaming activity on the VoD commercial activity, as well as the role of indirect «sampling » in the shaping of adoption trajectories. To do so, we have focused on the case of sequential adoption of two digital goods by taking the example of TV series with multiple episodes.

Our model reveals the existence of two opposite effects, namely « direct piracy » effect and « differential sampling » effect. The combination of both effects directly impacts on the outcome of the VoD commercial provider. A main result is that the VoD commercial provider's account for indirect « sampling » in her pricing decision-making leads her to increase her profit, all other things being equal. Moreover, we find that the setting out of non-linear (i.e., increasing or decreasing) pricing rules enables her to extract a higher surplus than that she would get if linear ones are preferred. However, such pricing strategies are not always found to allow her to benefit from illegal activities. Indeed, we have identified specific settings in which the "direct piracy » effect overcomes the "differential sampling » effect. In such settings, the introduction of the illegal downloading/streaming leads her to lower-leveled profits.

From a regulatory point of view, the results of our model stress that outlaw activities are not likely to influence welfare levels. Although outlaw activities decrease the levels of profit reached by commercial players, they enable adopters to increase their surplus. Such welfare levels rather depend on the way commercial players consider learning effects - here « indirect sampling » - to set out pricing strategies. As a consequence, the public policies led to evict outlaw players from the market are not here found to be suitable for welfareenhancing purposes. On the contrary, commercial players have been shown to be key players in the improvement of welfare levels. As such, relevant public efforts could be carried out to help commercial players to identify external (e.g., illegal) distribution channels so that these could revise their pricing strategies.

Focussing on indirect « sampling », our results contrast with previous findings that have stressed that - direct - « sampling » effects may overcome « competition » effects (Bounie et al., 2005; Peitz and Waelbroeck, 2006b). Our findings thus reveal that the impact of « sampling » on commercial outcomes is not the same in the case of music and in the case of TV series with multiple episodes. We therefore suggest that further piracy-related analyses should establish a clear distinction between «sampling » and indirect «sampling », inasmuch as the scope of two such effects is likely to differ.

The study we have carried out nevertheless has some limitations. First of all, we have defined our model so as to analyze the sequential adoption trajectories of two products. Studying such patterns on the long run would allow us to 
better understand the role of indirect « sampling » on commercial outcomes when illegal downloading/streaming is possible. By considering an oligopolistic framework in which several $\mathrm{VoD}$ commercial providers compete, we would secondly be able to more precisely identify the impact of illegal activities on profits when network effects apply. One may finally find appropriate to introduce both direct and indirect « sampling » when studying adoption issues and ensuing outcomes in a context in which piracy cannot be prevented. Indeed, although we have stated that «sampling » is likely to be weaker than indirect "sampling » in the case of TV series with multiple episodes, it appears relevant to analyze the impact of the combination of both effects on profits and welfare.

The analysis of piracy-related tracks therefore leaves room for further research. As many contributions have already underlined, we find that commercial players remain able to design suitable - here pricing - strategies to develop in the so-called « hostile » environment in which they are nowadays likely to evolve, while the recent public policies carried out to prevent illegal activities have been shown to have no effect on welfare levels. As such, the cultural goods market may be somehow seen as an ecosystem in which commercial players have to adapt to the development of external activities.

\section{REFERENCES}

ALCALÁ F. and GONZÁLEZ-MAESTRE M. (2010), « Copying, Superstars, and Artistic Creation », Information Economics and Policy, vol. 22, n 4, pp. 365-378.

BANERJEE B.-S., BANERJEE T. and RAYCHAUDHURI A. (2008), « Optimal Enforcement and Anti-Copying Strategies to Counter Copyright Infringement », Japanese Economic Review, vol. 59, n 4, pp. 519-535.

BELLEFLAMME P. and PEITZ M. (2010), « Digital Piracy: Theory », CORE Discussion Paper 2010/60.

BESEN S.-M. and KIRBY S.-N. (1989), « Private Copying, Appropriability, and Optimal Copying Royalties », Journal of Law and Economics, vol. 32, n 2, pp. 255-280.

BOUNIE D., BOURREAU M. and WAELBROECK P. (2005), «Pirates or Explorers? Analysis of Music Consumption in French Graduate Schools », Working paper EC-05-01, ENST Paris, Paris, France.

BOUNIE D., BOURREAU M. and WAELBROECK P. (2006), « Piracy and the Demand for Films : Analysis of Piracy Behavior in French Universities », Review of Economic Research on Copyright Issues, vol. 3, $\mathrm{n}^{\circ} 2$, pp. 15-27. 
CHELlAPPA R.-K. and SHIVENDU S. (2005), « Managing Piracy: Pricing and Sampling Strategies for Digital Experience Goods in Vertically Segmented Markets », Information Systems Research, vol. 16, ${ }^{\circ}$ 4, pp. 400-417.

CONNER K.-R. and RUMELT R.-P. (1991), « Software Piracy - An Analysis of Protection Strategies », Management Science, vol. 37, $\mathrm{n}^{\circ}$ 2, pp. 125-139.

DANAHER B., DHANASOBHON S., SMITH M.-D. and TELANG R. (2010), « Converting Pirates Without Cannibalizing Purchasers: The Impact of Digital Distribution on Physical Sales and Internet Piracy », Marketing Science, vol. 29, n 6, pp. 1138-1151.

FLOWERS S. (2008), « Harnessing the Hackers: The Emergence and Exploitation of Outlaw Innovation », Research Policy, vol. 37, n 2, pp. 177-193.

GAYER A. and SHY O. (2006), « Publishers, Artists, and Copyright Enforcement », Information Economics and Policy, vol. 18, $\mathrm{n}^{\circ} 4$, pp. 374-384.

GOPAL R.-D., BHATTACHARJEE S. and SANDERS G.-L. (2006), « Do Artists Benefit From Online Music Sharing ? », Journal of Business, vol. 79, n 4, pp. 1503-1534.

von HIPPEL E. (1988), The Sources of Innovation, Oxford University Press, New York, NY.

von HIPPEL E. (2005), Democratizing Innovation, MIT Press, Cambridge, MA.

HUI K.-L. and PNG I. (2003), «Piracy and the Legitimate Demand for Recorded Music », Contributions to Economic Analysis and Policy, vol. 2, $\mathrm{n}^{\circ}$ 1, pp. 1-11.

LIEBOWITZ S.-J. (1985), « Copying and Indirect Appropriability: Photocopying of Journals », Journal of Political Economy, vol. 93, $\mathrm{n}^{\circ}$ 5, pp. 945-957.

LIEBOWITZ S.-J. (2006), « File-Sharing: Creative Destruction or Just Plain Destruction? », Journal of Law and Economics, vol. 49, $\mathrm{n}^{\circ}$ 1, pp. 1-28.

PARK Y. and SCOTCHMER S. (2005), « Digital Rights Management and the Pricing of Digital Products », NBER Working Papers 11532.

PEITZ M. and WAELBROECK P. (2006a), «Piracy of Digital Products : A Critical Review of the Theoretical Literature », Information Economics and Policy, vol. 18, n ${ }^{\circ} 4$, pp. 449-476.

PEITZ M. and WAELBROECK P. (2006b), « Why the Music Industry May Gain From Free Downloading - The Role of Sampling », International Journal of Industrial Organization, vol. 24, n 5, pp. 907-913.

SHAPIRO C. and VARIAN H.-R. (1998), Information Rules : A Strategic Guide to the Network Economy. Harvard Business School Press, Cambridge, MA.

SHY O. and THISSE J. (1999), « A Strategic Approach to Software Protection », Journal of Economics and Management Strategy, vol. 8, $\mathrm{n}^{\circ}$ 2, pp. 163-190.

SMITH M.-D. and TELANG R. (2010), « Piracy or Promotion? The Impact of Broadband Internet Penetration on DVD Sales », Information Economics and Policy, vol. 22, $\mathrm{n}^{\circ} 4$, pp. 289-298.

TAKEYAMA L.-N. (1994), «The Welfare Implications of Unauthorized Reproduction of Intellectual Property in the Presence of Network Externalities », Journal of Industrial Economics, vol. $42, \mathrm{n}^{\circ}$ 2, pp. 155-166.

TOFFLER A. (1980), The Third Wave, William Morrow and Co., New York, NY.

VARIAN H.-R. (2000), "Buying, Sharing and Renting Information Goods », Journal of Industrial Economics, vol. 48, $\mathrm{n}^{\circ}$ 4, pp. 473-488.

ZENTNER A. (2006), « Measuring the Effect of Music Downloads on Music Purchases », Journal of Law and Economics, vol. 49, $\mathrm{n}^{\circ}$ 1, pp. 63-90. 


\section{APPENDICES}

\section{Appendix 1: Proof of Lemma 1}

The VoD commercial provider sets her prices so that $u\left(b_{1} ; b_{2}\right) \geq u\left(\varnothing_{1} ; \varnothing_{2}\right)$ and $u\left(b_{1} ; b_{2}\right) \geq u\left(b_{1} ; \varnothing_{2}\right)$. The VoD commercial provider sets her prices so that she builds a lock-in strategy according to which adopters are always willing to purchase product 2 if she has previously purchased product 1 . To extract the expected surplus from the adopters, the $\mathrm{VoD}$ commercial provider sets $\left(p_{1}^{*} ; p_{2}^{*}\right)$ so that $u\left(b_{1} ; b_{2}\right)=u\left(\varnothing_{1} ; \varnothing_{2}\right)$ and $u\left(b_{1} ; b_{2}\right)=u\left(b_{1} ; \varnothing_{2}\right)$. We find that $\left(p_{1}^{*} ; p_{2}^{*}\right)=(r+\alpha / 2-t / 4 ; r+\alpha / 2-t / 4)$. At such price levels, we observe that $u\left(b_{1} ; b_{2}\right)=u\left(\varnothing_{1} ; b_{2}\right)$. All the constraints being satured, the setting out of the linear pricing rule we identify allows the VoD commercial provider to fully serve the market. As a consequence, the profit-maximizing firm makes here profit $\pi^{*}=2 r+\alpha-t / 2-K$ by setting out $\left(p_{1}^{*} ; p_{2}^{*}\right)=(r+\alpha / 2-$ $t / 4 ; r+\alpha / 2-t / 4)$.

\section{Appendix 2: Proof of Lemma 2}

As stated in the case in which "sampling » is not introduced, the VoD commercial provider sets her prices so that $u\left(b_{1} ; b_{2}\right) \geq u\left(\varnothing_{1} ; \varnothing_{2}\right)$ and $u\left(b_{1} ; b_{2}\right)$ $\geq u\left(b_{1} ; \varnothing_{2}\right)$. To extract the expected surplus from the adopters, the VoD commercial provider sets $\left(p_{1}^{*} ; p_{2}^{*}\right)$ so that $u\left(b_{1} ; b_{2}\right)=u\left(\varnothing_{1} ; \varnothing_{2}\right)$ and $u\left(b_{1} ; b_{2}\right)=$ $u\left(b_{1} ; \varnothing_{2}\right)$. We find that $\left(p_{1}^{*} ; p_{2}^{*}\right)=(r+\alpha / 2-t / 4 ; r+\alpha / 2-t / 4 N)$. At such price levels, we observe that $u\left(b_{1} ; b_{2}\right)>u\left(\varnothing_{1} ; b_{2}\right)$. Hence, the setting out of such a pricing strategy allows the $\mathrm{VoD}$ commercial provider to fully serve the market. The profit-maximizing firm makes here profit $\pi^{*}=2 r+\alpha-t / 4-t / 4 N$ $-K$ by setting out $\left(p_{1}^{*} ; p_{2}^{*}\right)=(r+\alpha / 2-t / 4 ; r+\alpha / 2-t / 4 N)$.

\section{Appendix 3: Proof of Lemma 3}

The VoD commercial provider sets her prices so that:

$$
\left\{\begin{array} { l } 
{ u ( b _ { 1 } ; b _ { 2 } ) \geq u ( \varnothing _ { 1 } ; \varnothing _ { 2 } ) } \\
{ u ( b _ { 1 } ; b _ { 2 } ) \geq u ( d _ { 1 } ; d _ { 2 } ) } \\
{ u ( b _ { 1 } ; b _ { 2 } ) \geq u ( d _ { 1 } ; \varnothing _ { 2 } ) } \\
{ u ( b _ { 1 } ; b _ { 2 } ) \geq u ( \varnothing _ { 1 } ; d _ { 2 } ) } \\
{ u ( b _ { 1 } ; b _ { 2 } ) \geq u ( b _ { 1 } ; \varnothing _ { 2 } ) } \\
{ u ( b _ { 1 } ; b _ { 2 } ) \geq u ( b _ { 1 } ; d _ { 2 } ) }
\end{array} \Leftrightarrow \left\{\begin{array}{l}
2 r+\alpha-t / 2 \geq p_{1}+p_{2} \\
\alpha+2 s \geq p_{1}+p_{2} \\
r+\alpha-t / 4+s \geq p_{1}+p_{2} \\
r+\alpha / 2-t / 4 \geq p_{2} \\
\alpha / 2+s \geq p_{2}
\end{array}\right.\right.
$$

To extract the expected surplus from the adopters, we find that the VoD commercial provider sets $\left(p_{1}^{*} ; p_{2}^{*}\right)=(\alpha / 2+s ; \alpha / 2+s)$. At such price levels, we observe that $u\left(b_{1} ; b_{2}\right) \geq u\left(\varnothing_{1} ; b_{2}\right)$ and $u\left(b_{1} ; b_{2}\right)=u\left(d_{1} ; b_{2}\right)$. The setting out of such a pricing strategy allows the $\mathrm{VoD}$ commercial provider to 
fully serve the market. The profit-maximizing firm makes here profit $\pi^{*}=\alpha+$ $2 s-K$ by setting out $\left(p_{1}^{*} ; p_{2}^{*}\right)=(\alpha / 2+s ; \alpha / 2+s)$.

\section{Appendix 4: Proof of Lemma 4}

The VoD commercial provider sets her prices so that:

$$
\left\{\begin{array} { l } 
{ u ( b _ { 1 } ; b _ { 2 } ) \geq u ( \varnothing _ { 1 } ; \varnothing _ { 2 } ) } \\
{ u ( b _ { 1 } ; b _ { 2 } ) \geq u ( d _ { 1 } ; d _ { 2 } ) } \\
{ u ( b _ { 1 } ; b _ { 2 } ) \geq u ( d _ { 1 } ; \varnothing _ { 2 } ) } \\
{ u ( b _ { 1 } ; b _ { 2 } ) \geq u ( \varnothing _ { 1 } ; d _ { 2 } ) } \\
{ u ( b _ { 1 } ; b _ { 2 } ) \geq u ( b _ { 1 } ; \varnothing _ { 2 } ) } \\
{ u ( b _ { 1 } ; b _ { 2 } ) \geq u ( b _ { 1 } ; d _ { 2 } ) }
\end{array} \Leftrightarrow \left\{\begin{array}{l}
2 r+\alpha-t / 4-t / 4 N \geq p_{1}+p_{2} \\
\alpha+t / 8-t / 4 N+2 s \geq p_{1}+p_{2} \\
r+\alpha-t / 4 N+s \geq p_{1}+p_{2} \\
r+\alpha / 2-t / 4 N \geq p_{2} \\
\alpha / 2+s \geq p_{2}
\end{array}\right.\right.
$$

To extract the expected surplus from the adopters, we find that the VoD commercial provider sets $\left(p_{1}^{*} ; p_{2}^{*}\right)=(\alpha / 2+s+t / 8-t / 4 N ; \alpha / 2+s)$. At such price levels, we observe that $u\left(b_{1} ; b_{2}\right) \geq u\left(\varnothing_{1} ; b_{2}\right)$ and $u\left(b_{1} ; b_{2}\right)=u\left(d_{1}\right.$; $b_{2}$ ). The setting out of such a pricing strategy allows the VoD commercial provider to fully serve the market. The profit-maximizing firm makes profit $\pi^{*}=$ $\alpha+2 s+t / 8-t / 4 N-K$ by setting out $\left(p_{1}^{*} ; p_{2}^{*}\right)=(\alpha / 2+s+t / 8-t / 4 N ; \alpha / 2+s)$. 